Z. WANG, S. PATNAIK, N. EEDUGURALA, J. S. MANZANO, I. I. SLOWING, T. KOBAYASHI, A. D. SADOW*, M. PRUSKI* (U.S. DEPARTMENT OF ENERGY AND IOWA STATE UNIVERSITY, AMES, USA)

Silica-Supported Organolanthanum Catalysts for C-O Bond Cleavage in Epoxides

J. Am. Chem. Soc. 2020, 142, 2935-2947.

\title{
Ring-Opening Hydroboration of Epoxides Catalyzed by a Silica-Supported Organolanthanum Complex
}

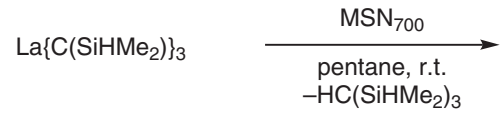

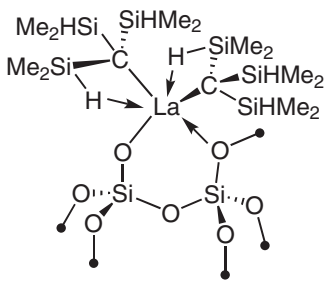

[La]@MSN $\mathrm{MSO}_{700}$

$\mathrm{MSN}_{700}$ : mesoporous silica nanoparticles calcinated at $700{ }^{\circ} \mathrm{C}$

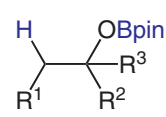

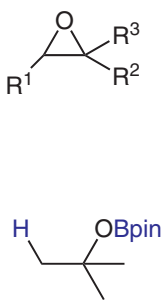

$100 \%$ NMR yield

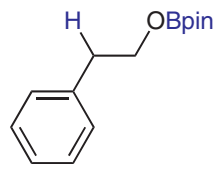

$100 \%$ NMR yield

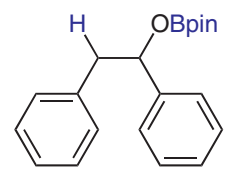

$100 \%$ NMR yield

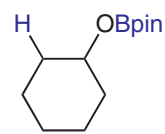

$98 \%$ NMR yield
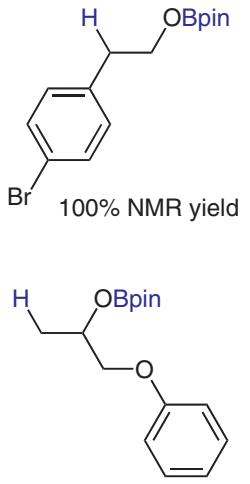

97\% NMR yield

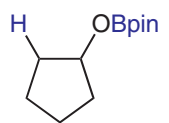

$85 \%$ NMR yield $\left(60^{\circ} \mathrm{C}\right)$
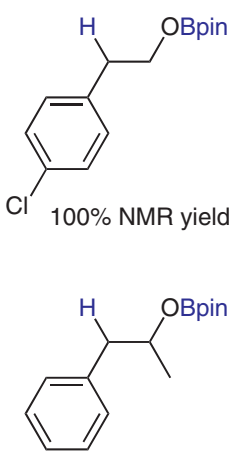

$87 \%$ NMR yield

\section{Category}

Polymer-Supported

Synthesis

\section{Key words}

lanthanum catalysis

mesoporous silica

hydroboration

epoxides

\section{Synfact 1 of the 4 Month}

Significance: An organolanthanum complex immobilized on mesoporous silica nanoparticles ([La]@MSN $\mathrm{H}_{700}$ ), prepared as shown in equation 1, catalyzed the ring-opening hydroboration of epoxides with pinacolborane to give the corresponding boryl ethers in $87-100 \%$ NMR yield (eq. 2).
Comment: [La]@MSN 700 was characterized by means of mass balance of grafting, surface alcoholysis reactions, elemental analysis, and DRIFTS, STEM, EDX, and SSNMR spectroscopies. In the reaction of styrene oxide with pinacolborane, the catalyst was reused five times with a gradual loss of its catalytic activity. 